\title{
Fetal transcerebellar diameter nomogram in Nepalese population
}

\author{
B. R. Joshi \\ Department of Radiology and Imaging, Tribhuvan University Teaching Hospital, Kathmandu, Nepal.
}

Correspondance to : B. R. Joshi, Department of Radiology and Imaging, Tribhuvan University Teaching Hospital, Kathmandu, Nepal

Email: bjoshi01@yahoo.com

\begin{abstract}
Introduction: Sonographic determination of gestational age (GA) is becoming increasingly important. Many parameters can be used for establishing GA. The transverse cerebellar diameter (TCD) is a reliable parameter for estimating it. Fetal cerebellum grows progressively along with GA and can predict GA at any trimester. This study was undertaken to construct an institution specific Transcerebellar diameter (TCD) nomogram and to compare its ability to predict gestational age with previously published nomograms.
\end{abstract}

Methods: A cross-sectional nomogram was constructed using TCD measurements of 594 singleton fetuses in Nepalese population by using linear regression model. Measurements were obtained by placing the calipers of the ultrasound machine at the outer - to- outer margins of the cerebellum. The suitability of previously established TCD nomograms for predicting gestational age was assessed in Nepalese population to determine comparability between nomograms.

Results: Gestational age and TCD $50^{\text {th }}$ percentile in mm coincided well till $20^{\text {th }}$ week of gestation. Between $21^{\text {st }}$ to $28^{\text {th }}$ weeks of gestation, there were no clinically important differences between our nomogram and previously published in terms of the predicted gestational age. However, predicted gestational age in third trimester was considerably different by using our nomogram by 1-2 weeks from 29-32 weeks and by 3-6 weeks after 33 weeks. There were differences of 4-6 mm between 29-32 weeks and of 7-11 mm after 33 weeks.

Conclusions: TCD measurements had a similar relationship with gestational age across previously published nomograms before 28 weeks. Significant differences occurred in predicting gestational age after 33 weeks.

Keywords: Gestational age, nomogram, transcerebellar diameter, ultrasound

\section{Introduction}

Estimation of length of gestation is of critical importance in clinical practice to ensure appropriate management of newborns and to distinguish pre-term from term infants. Low birth weight, a common problem in developing countries, is due to either short gestation or to being small or light-for-date. Clinical problems encountered with short gestation (pre-term) whose birth weights match their GA are hyaline membrane disease and infection. Small for dates, whether pre-term or term, are liable to suffer from asphyxia and hypoglycemia during the course of labor and immediately post-delivery. In addition, post-maturity problems may arise when mothers are not aware of last menstrual period (LMP) and appropriate care is not provided to reduce complications such as asphyxia or hypoglycemia. ${ }^{1}$

Despite recognition that estimation of GA based on maternal recollection of the LMP is fraught with error, it is not generally appreciated that the magnitude and direction of 
this error vary as a function of LMP estimate. Early secondtrimester (16-18 weeks) ultrasound determinations of the fetal BPD (Biparietal Diameter) were used as the 'gold standard' to test the validity of LMP-based GA estimates in 11,045 women. The large majority of deliveries occurring at or near term showed LMP estimates that were valid within plus or minus 7 days of the ultrasound estimate. As the LMP- GA deviated progressively toward earlier or later gestational ages, however, the discrepancies became quite marked, especially for post term dates. The positive predictive values of the LMP GA estimates decreased dramatically from term $(0.949)$ to pre-term $(0.755)$ to post term (0.119) deliveries. These systematic errors in menstrual GA estimates have profound implications for unnecessary induction, dysfunctional labor and cesarean section, and resultant neonatal and maternal morbidity. Regardless of the explanation, the overall validity of menstrual dating will appear to be high, because the vast majority of babies are born at or near term. This is misleading, however, because it is precisely in pregnancies in which menstrual dating suggests pre-term labor or post term non-labor that accurate GA estimation is greatest clinical importance. ${ }^{2}$

Sonographic determination of gestational age (GA) is becoming increasingly important. Many parameters can be used for establishing GA. The transverse cerebellar diameter (TCD) is a reliable parameter for estimating gestational age. ${ }^{3}$ TCD can predict GA especially in cases where there is variation of fetal head shape. Cerebellum is not liable to change in its form and its size correlates with GA. Fetal cerebellar diameter in normal gestation is highly correlated with fetal growth indices. It is least affected in cases of growth retardation. ${ }^{4}$ The aim of this study was to construct an institution specific TCD nomogram and to compare its ability to predict gestational age with previously published nomograms.

\section{Methods}

This study was performed on 594 patients who came for ultrasonography in Department of Radiology and Imaging, Tribhuvan University Teaching Hospital, Kathmandu, Nepal, from January to December 2007. The measurements were obtained with commercially available, curvilinear array real time, B-mode ultrasound, equipped with a $3.5 \mathrm{MHz}$ transducer (Sonace 8800 Medison and Aloka 1000 machines). Participants were explained about the procedure and it was performed in supine position with hips and knees in extension. The probe was held with right hand and the same observer performed all the measurements in millimeters. Specific methods regarding imaging criteria, caliper placement, and averaging of at least two measurements for each were followed. Transverse views of the fetal intracranial anatomy were obtained (Fig. 1). Measurements were obtained by placing the calipers of the ultrasound machine at the outer-to-outer margins of the cerebellum. Only fetuses with a last menstrual period gestational age confirmed by ultrasound were used. A cross-sectional TCD nomogram was constructed by using recorded TCD measurements. A single measurement was used for each patient. Only last TCD measurement was used in the nomogram construction in case of fetuses with multiple measurements at different gestational ages. To decrease the inter-observer variability, a single radiologist performed the measurements. To decrease the intra-observer variability the average value of the two measurements was used.

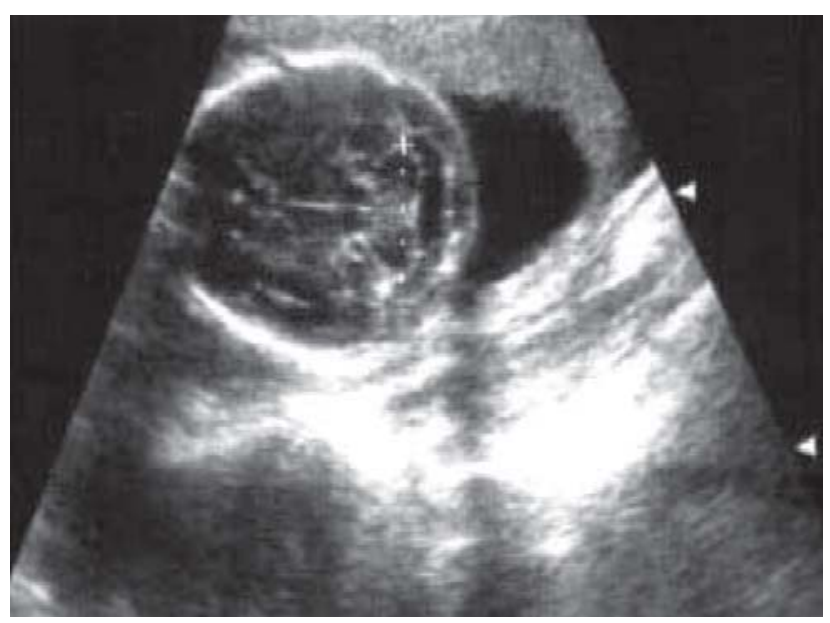

Fig. 1: Measurement of TCD (Measurements were obtained by placing the calipers of the ultrasound machine at the outer-to-outer margins of the cerebellum).

To construct the TCD nomogram, separate linear regression models for the mean and SD were fit on the basis of gestational age. The number of TCD measurements at each week of gestation varies. There is more variability in TCD measurements with increasing gestational age. Differences in the performance in prediction of GA between our nomogram and previously published nomograms were compared. At each given TCD measurement, the GA was assessed. The difference between predicted GA at each TCD measurement for our nomogram versus the other nomograms was performed.

\section{Results}

There were 594 singleton fetuses that met inclusion criteria for this study. TCD measurements for gestational ages from 15 to 38 weeks were available for construction of the nomogram (Table 1). With the use of regression equation, the predicted TCD for the $5^{\text {th }}, 50^{\text {th }}$ and $95^{\text {th }}$ centiles were calculated for each GA (Table 2). 
Fetal transcerebellar diameter

Table 1: The transverse cerebellar diameter (TCD) data

\begin{tabular}{|c|c|c|c|c|c|c|c|c|c|c|c|c|c|}
\hline \multirow[t]{2}{*}{$\begin{array}{l}\text { GA } \\
\text { (wks) }\end{array}$} & \multirow[t]{2}{*}{$\mathrm{N}$} & \multirow{2}{*}{$\begin{array}{l}\text { This } \\
\text { study } \\
\text { mean }\end{array}$} & \multirow[t]{2}{*}{ SD } & \multirow[t]{2}{*}{ SÉ } & \multirow[t]{2}{*}{ Chavez7 } & \multicolumn{3}{|c|}{ TCD centile } & \multirow[t]{2}{*}{$\begin{array}{l}\text { Estima- } \\
\text { ted }\end{array}$} & \multirow[t]{2}{*}{$P$} & \multirow[t]{2}{*}{ MD } & \multicolumn{2}{|c|}{$\begin{array}{l}95 \% \text { CI of } \\
\text { mean } \\
\text { difference }\end{array}$} \\
\hline & & & & & & 5 & 50 & 95 & & & & $\begin{array}{l}\text { Lower } \\
\text { limit }\end{array}$ & $\begin{array}{l}\text { Upper } \\
\text { limit }\end{array}$ \\
\hline & & & & & & & & & & & & & \\
\hline 15 & 3 & 1567 & 3055 & 18 & 15 & 13 & 15 & 10 & 1204 & 444 & 167 & 507 & 026 \\
\hline 16 & 6 & 38.71 & 1.722 & 0.7 & 16 & 14 & 16 & 19 & 14.57 & .822 & 0.17 & -1.64 & 1.97 \\
\hline 17 & 6 & 36.56 & 3.386 & 1.4 & 17 & 14 & 17 & 24 & 16.1 & .650 & 0.67 & -2.89 & 4.22 \\
\hline 18 & 14 & 40.15 & 1.950 & 0.5 & 18 & 16 & 18 & 24 & 17.63 & .293 & 0.57 & -0.55 & 1.70 \\
\hline 19 & 27 & 43.13 & 1.920 & 0.4 & 19 & 16 & 19 & 25 & 19.16 & .843 & 0.07 & -0.69 & 0.83 \\
\hline 20 & 20 & 46.32 & 1.373 & 0.3 & 20 & 17 & 20 & 23 & 20.69 & .748 & 0.10 & -0.74 & 0.54 \\
\hline 21 & 20 & 51.92 & 2.222 & 0.5 & 22 & 18 & 22 & 28 & 22.22 & .843 & -0.10 & -1.14 & 0.94 \\
\hline 22 & 16 & 55.31 & 4.986 & 1.2 & 23 & 19 & 23 & 28 & 23.75 & .407 & 1.06 & -1.59 & 3.72 \\
\hline 23 & 19 & 54.84 & 2.183 & 0.5 & 24 & 19 & 24 & 28 & 25.28 & .836 & 0.11 & -0.95 & 1.16 \\
\hline 24 & 12 & 58.82 & 1.586 & 0.5 & 26 & 23 & 26 & 28 & 26.81 & .096 & 0.83 & -0.17 & 1.84 \\
\hline 25 & 11 & 60.19 & 1.191 & 0.4 & 28 & 26 & 28 & 29 & 28.34 & .465 & -0.27 & -1.07 & 0.53 \\
\hline 26 & 12 & 62 & 3.554 & 1.0 & 29 & 18 & 28 & 31 & 29.87 & .67 & -2.08 & -4.34 & 0.17 \\
\hline 27 & 17 & 64.65 & 5.187 & 1.3 & 31 & 18 & 31 & 38 & 31.4 & .522 & -0.82 & $\begin{array}{l}-3.49 \\
\end{array}$ & 1.84 \\
\hline 28 & 13 & 68.43 & 2.570 & 0.7 & 33 & 28 & 33 & 38 & 32.93 & .529 & -0.46 & -2.01 & 1.09 \\
\hline 29 & 15 & 70.79 & 4.978 & 1.3 & 35 & 27 & 34 & 51 & 34.46 & .839 & 0.27 & -2.49 & 3.02 \\
\hline 30 & 19 & 72.27 & 4.621 & 1.1 & 37 & 24 & 35 & 45 & 35.99 & .213 & -1.37 & -3.60 & 0.86 \\
\hline 31 & 22 & 75.96 & 4.235 & 1 & 40 & 28 & 38 & 45 & 37.52 & .052 & -1.86 & -3.74 & 0.01 \\
\hline 32 & 23 & 78.39 & 3.643 & 0.7 & 42 & 31 & 41 & 45 & 39.05 & .015 & -2.00 & -3.58 & -0.42 \\
\hline 33 & 20 & 80.59 & 8.514 & 2.7 & 45 & 29 & 47 & 60 & 40.58 & .885 & -0.40 & -6.49 & 5.69 \\
\hline 34 & 32 & 78.16 & 4.581 & 4.6 & 48 & 34 & 43 & 50 & 42.11 & .000 & -5.32 & -7.35 & -3.69 \\
\hline 35 & 18 & 83.64 & 8.210 & 2.9 & 51 & 23 & 44 & 48 & 43.64 & .013 & -9.63 & -16.49 & -2.76 \\
\hline 36 & 18 & 82.78 & 9.517 & 3.4 & 54 & 28 & 45 & 54 & 45.17 & .017 & -10.50 & -18.46 & -2.54 \\
\hline 37 & 14 & 85.85 & 9.076 & 2.4 & 57 & 29 & 46 & 59 & 46.7 & .000 & -11.71 & -16.95 & -6.47 \\
\hline 38 & 17 & 88 & 7.994 & 3.0 & 61 & 37 & 51 & 60 & 48.23 & .028 & -8.71 & -16.11 & -1.32 \\
\hline
\end{tabular}

Table 2: Regression equations derived from study for predicting fetal parameter TCD from GA

$\begin{array}{lll}\text { Parameter } & \text { Regression Equation } & \mathbf{R}^{2}[\%] \\ \text { TCD } & \text { TCD }=-9.91+1.53 \mathrm{GA} & 82 \\ \text { TCD } & \text { TCD }=1.71+0.62 \mathrm{GA}-1.02 \mathrm{GA}^{2} & 82 \\ \text { TCD } & \text { TCD }=34.38-3.32 \mathrm{GA} & \\ & +0.17 \mathrm{GA}^{2}-0.002 \mathrm{GA}^{3} & 83\end{array}$

Regression analysis focuses on the form of the relationship between variables, while the objective of correlation analysis is to gain insight into the strength of the relationship. Coefficient of determination $\left(\mathrm{R}^{2}\right)$ is the fraction of variability in \% that can be explained by the variability in $\mathrm{x}$ through their linear relationship or vice versa. ${ }^{5}$

TCD showed linear correlation with advancing fetal age. Collected data was converted into variables which were analysed by Statistical package for social sciences (SPSS). Predicted values were obtained for Nepalese population by using the regression equation (Table 3). Sonographic sizes of the cerebellum increased linearly during the second trimester and at a faster rate at third trimester. 
Table 3: PredictedTCD in Nepalese population

\begin{tabular}{|c|c|}
\hline GA & TCD \\
\hline 13 & 9.98 \\
\hline 14 & 11.51 \\
\hline 15 & 13.04 \\
\hline 16 & 14.57 \\
\hline 17 & 16.1 \\
\hline 18 & 17.63 \\
\hline 19 & 19.16 \\
\hline 20 & 20.69 \\
\hline 21 & 22.22 \\
\hline 22 & 23.75 \\
\hline 23 & 25.28 \\
\hline 24 & 26.81 \\
\hline 25 & 28.34 \\
\hline 26 & 29.87 \\
\hline 27 & 31.4 \\
\hline 28 & 32.93 \\
\hline 29 & 34.46 \\
\hline 30 & 35.99 \\
\hline 31 & 37.52 \\
\hline 32 & 39.05 \\
\hline 33 & 40.58 \\
\hline 34 & 42.11 \\
\hline 35 & 43.64 \\
\hline 36 & 45.17 \\
\hline 37 & 46.7 \\
\hline 38 & 48.23 \\
\hline 39 & 49.76 \\
\hline 40 & 51.29 \\
\hline 41 & 52.82 \\
\hline 42 & 54.35 \\
\hline
\end{tabular}

The difference in millimeters of our measurement for each GA was compared with data from other nomograms (Table 4). ${ }^{6-11}$ Gestational age and TCD $50^{\text {th }}$ percentile in mm coincided well till $20^{\text {th }}$ week of gestation. Between $21^{\text {st }}$ to $28^{\text {th }}$ weeks of gestation, there were no clinically important differences between our nomogram and previously published in terms of the predicted gestational age. However, predicted gestational age in third trimester was considerably different in comparison to our nomogram by 1-2 weeks from 29-32 weeks and by 3-6 weeks after 33 weeks. There was difference of 4-6 mm between 29-32 weeks and of 7-11 mm after 33 weeks when compared with that of Chavez. ${ }^{10}$
Table 4: Comparison of new with established TCD nomograms by GA

\begin{tabular}{|c|c|c|c|c|c|c|}
\hline \multirow{2}{*}{$\begin{array}{l}\text { TCD 50 } \\
\text { PERCENTILE } \\
\text { [MM] }\end{array}$} & & \multicolumn{5}{|c|}{ PREDICTED GA [WEEK] } \\
\hline & Current & \multicolumn{5}{|c|}{ Chavez Goldstein Altman Snijders Hil } \\
\hline 14 & 16 & 14 & & 15 & 14 & 15 \\
\hline 15 & 16 & 15 & 15 & 16 & 15 & 15 \\
\hline 16 & 17 & 16 & 16 & 17 & 16 & 16 \\
\hline 17 & 17 & 17 & 17 & 18 & 17 & 17 \\
\hline 18 & 18 & 18 & 18 & 19 & 18 & 18 \\
\hline 19 & 19 & 19 & 19 & 20 & 19 & 19 \\
\hline 20 & 20 & 20 & 20 & 21 & 19 & 19 \\
\hline 22 & 21 & 21 & 21 & 22 & 21 & 21 \\
\hline 23 & 22 & 22 & 22 & 23 & 21 & 21 \\
\hline 24 & 22 & 23 & 23 & 24 & 22 & 22 \\
\hline 26 & 23 & 24 & 24 & 25 & 24 & 23 \\
\hline 28 & 25 & 25 & 25 & 26 & 25 & 25 \\
\hline 29 & 26 & 26 & 26 & 27 & 26 & 26 \\
\hline 31 & 27 & 27 & 28 & 28 & 27 & 27 \\
\hline 33 & 28 & 28 & 29 & 30 & 29 & 28 \\
\hline 35 & 30 & 29 & 30 & 31 & 30 & 29 \\
\hline 37 & 31 & 30 & 31 & 33 & 32 & 30 \\
\hline 40 & 33 & 31 & 33 & 36 & 34 & 32 \\
\hline 42 & 34 & 32 & 36 & & 36 & 33 \\
\hline 45 & 36 & 33 & 37 & & 39 & 35 \\
\hline 48 & 38 & 34 & 38 & & & 36 \\
\hline 51 & 40 & 35 & 39 & & & 37 \\
\hline 54 & 42 & 36 & & & & 38 \\
\hline 57 & & 37 & & & & \\
\hline 61 & & 38 & & & & \\
\hline
\end{tabular}

\section{Discussion}

All would agree that ultrasonography plays a central role in modern obstetric practice and that ultrasonographic examination should be recommended when indicated and performed with women's consent. Most would agree that there are advantages to routine obstetric ultrasonographic examinations done once, at about 18 weeks. Campbell et al established that ultrasonographic measurement of GA between 12-18 weeks is superior to an optimal menstrual history in predicting the date of delivery. The American Institute of Ultrasound in Medicine assessed theoretical harms in its safety assessment and concluded that 'the benefits to patients of the prudent use of diagnostic ultrasound far outweighs any potential risk' ${ }^{12}$

Relative preservation of normal cerebellar growth is present in growth-restricted fetuses and a similar rate of growth in 
singleton and multifetal gestations. The transverse cerebellar diameter therefore represents an independent biometric parameter that can be used in both singleton and multifetal pregnancies to assess normal and deviant fetal growth. ${ }^{13}$

Chavez, M.R. et al conducted a study to construct an institution-specific transverse cerebellar diameter (TCD) nomogram and to compare its ability to predict GA with previously published nomograms. They suggested that institutions performing large numbers of fetal ultrasound examinations should derive TCD nomograms and perhaps nomograms for other fetal biometry for their own populations to determine the measurement standards most appropriate for clinical use. The specific TCD nomogram chosen for clinical application should be based on rigorous methods and large samples from populations that are as homogenous as possible. ${ }^{10}$

The differences with other nomograms may be due to the differences in sample size, unselected population, large number of third trimester fetuses, recent technological advancements in ultrasound and ethnic population variation. ${ }^{14}$ Similarity that of Goldstein may be due to similar sample size and distribution. ${ }^{13}$

\section{Conclusions}

TCD measurements had a similar relationship with gestational age across previously published nomograms before 28 weeks. Significant differences occurred in predicting gestational age after 33 weeks. The nomogram of Chavez significantly overestimated gestational age in the later part of third trimester from 34 weeks onwards. This supported the argument that there is a need to have our own nomogram.

\section{References}

1. Feresu SA, Gillespie BW, Sowers MF, Johnson TRB Welch K, et al. Improving the assessment of gestational age in Zimbabwean population. Intern J of Obs \& gyn. 2002;78:7-18.

2. Kramer MS, Mclean FM, Boyd ME, Usher RH. The validity of GA estimation by menstrual dating in term, preterm and post-term gestation. JAMA 1988; 260:3306.

3. Reece EA, Goldstein I, Pilu G. Fetal cerebellar growth unaffected by intrauterine growth retardation: a new parameter for prenatal diagnosis. Am J Obstet Gynecol 1987;157: 632-82.
4. Cambell WA, Vintzileos, Rodis JF. Use of transverse cerebellar diameter/abdominal circumference retardation. J Clin Ultrasound 1994;22:497-502.

5. Zou KH, Tuncali K, Silverman SG Correlation and simple linear regression. Radiology. 2003; 227:617-28.

6. Altman DG Chitty LS. New charts for ultrasound dating of pregnancy. Ultrasound Obstet Gynecol 1997;10: $174-91$.

7. Goldstein I, Reece EA, Pilu G. Cerebellar measurements with ultrasonography in the evaluation of fetal growth and development. Am J Obstet Gynecol 1987;156: 1065-9.

8. Altman DG Chitty IS. Charts for fetal size: methodology. BJOG 1994;101:29-34.

9. Snijders RJ, Nicolaides KH. Fetal biometry at 14 to 40 weeks of gestation. Ultrasound Obstet Gynecol 1994;4:34-8.

10. Chavez MR, Ananth CV, Smulian JC and et al. fetal transcerebellar diameter nomogram in singleton gestations with special emphasis in the third trimester: a comparison with previusly published nomograms. Am J of Obs \& Gyn.2003;89:1021-5.

11. Hill LM, Guzick D, Fries J. The transverse cerebellar diameter in estimating gestational age in the large for gestational age fetus. Obstet gynecol 1990;75;981-5.

12. Chervenak Fa, McCullough LB, Chervenak JL. Prenatal informed consent for sonogram; an indication for obstetric ultrasongraphy. Am J Obstet Gynecol. 1989; 161:857-60.

13. Goldstein I, Reece EA. Cerebellar growth in normal and growth restricted fetuses of multiple gestations. Am J Obstet Gynecol.1995;173:1343-8.

14. Dubowitz LM, Goldberg C. Assessment of gestation by ultrasound in various stages of pregnancy in infants differing in size and ethnic origin. BJOG 1981;88:255-9. 